\title{
Penerapan pertanian perkotaan untuk penguatan ketersediaan ruang terbuka hijau privat pada kota produksi penghasil minyak bumi di Duri Indonesia
}

\author{
Gendraya Rohaini $^{1}$, Sukendi ${ }^{2}$, Sofyan Siregar ${ }^{3}$, Dessy Yoswati ${ }^{4}$ \\ 1,2,3,4 Jurusan Ilmu Lingkungan, Program Pascasarjana Universitas Riau, Pekanbaru, Indonesia \\ *Correspondent email: Rohainifsf@gamail.com
}

Diterima: 19 Agustus 2021| Disetujui: 30 Oktober 2021 | Diterbitkan: 31 Oktober 2021

\begin{abstract}
Ministry of National Development Planning (PPN) / National Development Planning Agency (Bappenas), the Republic of Indonesia stated that Indonesia is committed to the environment in 2045 with a program towards Indonesia's Green Economy marked by a 41\% reduction in emissions. The existence of green open space (GOS) is an important factor in supporting the ecological sustainability of a city, The role of GOS in addition lies in improving temperature and humidity also found in the reduction of $\mathrm{CO}_{2}$ emissions. The main purpose of this research is to plan an integration strategy between GOS and the Urban Agriculture Program. in Duri City, Bengkalis Regency, Riau Province, which is one of the petroleum producing cities in Indonesia. The method of this research using GIS-AHP approach. The strategy action consists of environmental, economics and social commitments are maintained for development sustainability by implementing green technology, green economic regulation and strengthening the green community movement. The main result of research prove that strategic integration of GOS Privat with Urban Agriculture Program u in Duri City contributes GOS Private availability of $14,134 \%$, so that gos private has exceeded the requirement limit of at least $10 \%$ based on the mandate of the Spatial Arrangement Act, Republic of Indonesia.

Keywords: Petroleum producing cities; Green open space; Private; Urban agriculture; GIS; AHP
\end{abstract}

Kementerian Perencanaan Pembangunan Nasional (PPN)/Badan Perencanaan Pembangunan Nasional (Bappenas), Republik Indonesia menyatakan bahwa lima dari sebelas titik Mega Trend World 2045 adalah demografi global, urbanisasi dunia, peran ekonomi berkembang, perubahan iklim dan teknologi. Masih bersumber dari Bappenas bahwa populasi dunia pada tahun 2045 diperkirakan berjumlah sekitar 9,45 miliar dengan komposisi demografis penduduk dunia yang tinggal di daerah perkotaan mencapai sekitar $66 \%$ dan dari total populasi dunia, $55 \%$ berada di Asia. Tren demografi global ini akan mendorong urbanisasi, arus migrasi, dan lansia.

Proyeksi Perserikatan Bangsa-Bangsa mengantisipasi bahwa lebih dari dua pertiga populasi global akan tinggal di kota-kota pada tahun 2050 (Chandran, 2020; Loker dan Francis, 2020). Pesatnya perluasan pandemi COVID-19, menelan 186 negara antara Desember 2019 dan Maret 2020, telah memperburuk risiko kerawanan pangan berat/ekstrem dari 135 juta pada Januari 2020 menjadi 265 juta pada akhir 2020 (Dongyu, 2020; Lal,2020).

"Apa yang akan kita makan?" juga merupakan pertanyaan yang muncul sebagai penanda ancaman ketersediaan pangan untuk memenuhi kebutuhan seluruh populasi manusia di masa depan. Menurut data Global Hunger Index (GHI), tingkat kelaparan di Indonesia pada 2019 adalah 20,1 dan termasuk dalam kategori serius dengan 70 dari 117 negara. Data tersebut sebelum pandemi Covid-19 seperti sekarang. Tingkat kelaparan selama pandemi 2020 cenderung naik drastis (Dzulfaroh, 2019). Masalah ketersediaan pangan telah menjadi perhatian dunia, misalnya oleh Perserikatan Bangsa-Bangsa melalui Food and Agriculture Organization (FAO), yang merekomendasikan bahwa semua sektor pertanian perlu dikelola menggunakan teknologi inovatif.

Pertanian perkotaan merupakan salah satu komponen kunci pengembangan sistem pangan masyarakat berkelanjutan dan jika dirancang dengan tepat akan mampu meringankan masalah kerawanan pangan. Dengan kata lain, ketika pertanian perkotaan dikembangkan secara terintegrasi merupakan alternatif penting dalam mewujudkan pembangunan perkotaan berkelanjutan (Setiawan dan Rahmi, 2004). Lebih lanjut, Smith, dkk (2001) menyatakan bahwa 800 juta orang di seluruh dunia secara aktif terlibat dalam praktik pertanian perkotaan. Selanjutnya oleh Zezza dan Tasciotti (2010) bahwa pertanian perkotaan dapat menghasilkan rata-rata 15 hingga 20 persen dari produksi pangan dunia. Tingkat partisipasi masyarakat dalam kegiatan pertanian perkotaan di negara berkembang juga bervariasi, mulai dari $10 \%$ di Indonesia hingga hampir $70 \%$ di Vietnam dan Nikaragua. Peran pertanian perkotaan, ketika ditinjau dari aspek ekologis, dapat memberikan manfaat yaitu konservasi sumber daya tanah dan air, meningkatkan kualitas udara, menciptakan iklim mikro yang sehat, dan memberikan keindahan karena pertanian perkotaan sangat memperhatikan estetika (Blyth dan Menagh, 2006; Cofie, et al., 2006; Koscica, 
2014; Setiawan dan Rahmi, 2004; Wolfe dan Mc Cans, 2009) serta upaya mitigasi perubahan iklim (Specht, dkk., 2014).

Peran pertanian perkotaan dari aspek ekonomi memiliki banyak keunggulan, antara lain stimulus untuk memperkuat perekonomian lokal berupa membuka lapangan kerja baru, meningkatkan pendapatan masyarakat dan mengurangi kemiskinan. Sebuah studi tentang pertanian perkotaan di halaman rumah di Philadelphia Amerika Serikat (AS) menemukan bahwa orang-orang berpenghasilan rendah dengan pekarangan rumah dapat menghemat rata-rata $\$ 150$ setiap musim tanam (Pinderhughes, 2004).

Kota Daqing (China) dan Houston (Texas) adalah dua kota yang berkembang pesat karena aktivitas pertambangan oleh industri minyak bumi selama 50 tahun terakhir. Pembangunan tersebut dapat dilihat dari pemanfaatan lahan, perubahan dominan terjadi di lahan pedesaan, termasuk lahan pertanian dan hutan yang berubah dalam skala besar menjadi permukiman dalam waktu 30 tahun, yaitu dari tahun 1977 hingga 2007 (Yu, dkk, 2011). Selain dua kota penghasil minyak bumi yang diilustrasikan di atas, Kota Duri merupakan salah satu kota ladang minyak di Kabupaten Bengkalis Provinsi Riau, Indonesia. Lapangan Banjir Uap Duri telah dieksploitasi sejak tahun 50-an dan masih diproduksi oleh PT. Chevron Pacific

Karakter mendasar daerah perkotaan yang berkembang pesat akibat aktivitas pertambangan oleh industri minyak bumi merupakan kawasan dengan tingkat perkembangan yang tinggi disertai dengan peningkatan populasi yang cepat yang menyebabkan menurunnya kualitas lingkungan di kota dan meningkatnya tingkat kebutuhan lahan untuk bangunan Hal ini mengakibatkan menurunnya kualitas lingkungan perkotaan yang disebabkan oleh rendahnya kualitas air tanah, polusi udara tinggi dan kebisingan di kota. Tingginya frekuensi banjir di kota ini juga disebabkan oleh terganggunya sistem air akibat keterbatasan luas kandungan air dan tingginya volume air permukaan. Dampak besar dari pembangunan perkotaan menyebabkan RTH terlantar. Hilangnya RTH sangat mempengaruhi stabilitas ekosistem lingkungan, sekaligus meningkatkan polusi yang buruk bagi kesehatan masyarakat kota.

Deskripsi dari hilangnya RTH yang diilustrasikan di atas, berbeda dengan amanat UU Republik Indonesia No.26 Tahun 2007, tentang Penataan Ruang, pasal 29 ayat 1 dan 2 menyebutkan bahwa proporsi RTH di wilayah kota minimal $30 \%$ dari luas wilayah kota dan proporsi RTH publik di wilayah kota minimal $20 \%$ dari luas wilayah kota. Ketentuan tersebut juga tertuang dalam Peraturan Menteri Pekerjaan Umum Nomor 5 Tahun 2008 tentang Pedoman Penyediaan dan Pemanfaatan RTH di Perkotaan. Keberadaan RTH merupakan faktor penting dalam mendukung keberlanjutan ekologis suatu kota, selain itu keberadaan RTH juga mempengaruhi kenyamanan udara secara alami. Kenyamanan udara RTH dipengaruhi oleh suhu dan kelembaban yang dijelaskan dalam indeks kenyamanan termal. RTH dengan kondisi baik akan berkontribusi pada penurunan suhu udara 5,86\% dan peningkatan kelembaban 4\% (Asiani, 2007). Hal ini juga didukung oleh hasil penelitian yang menyatakan bahwa RTH dapat berperan dalam mengurangi efek Urban Heat Island (UHI) sehingga membuat kondisi perkotaan lebih sehat dan nyaman (Estoque, dkk., 2017). Peran RTH selain itu terletak pada peningkatan suhu dan kelembaban juga ditemukan dalam pengurangan emisi $\mathrm{CO}_{2}$. Rawung (2015) mengatakan dalam penelitiannya bahwa penyerapan RTH yang ada mampu mengurangi emisi $\mathrm{CO}_{2}$ aktual sekitar 119,73 hingga 271,18 ton/tahun.

Merujuk Badan Perencanaan Pembangunan Nasional (Bappenas), Republik Indonesia menyatakan bahwa Indonesia berkomitmen terhadap lingkungan hidup pada tahun 2045 dengan program menuju Ekonomi Hijau Indonesia yang ditandai dengan penurunan emisi sebesar $41 \%$ dan mandat RTH terhadap UU Republik Indonesia No.26 Tahun 2007, tentang Penataan Ruang terkait pelaksanaan dan realisasi RTH $30 \%$ dengan komposisi RTH Publik 20\% dan RTH Kota Duri yang merupakan salah satu penghasil sumber daya minyak bumi alam dikelola dan dimanfaatkan untuk kesejahteraan sebuah kota yang secara alami akan berpotensi mengurangi pola pemanfaatan lahan masyarakat. Oleh karena itu, perlunya integrasi implementasi pertanian perkotaan melalui penguatan RTH swasta 10\% diharapkan dapat menjadi solusi untuk meminimalisir permasalahan yang telah tergambar di atas, dalam upaya mewujudkan pembangunan perkotaan yang berkelanjutan.

\section{METODE PENELITIAN}

Penelitian ini menggunakan pendekatan teknik Geographic Information System (GIS) dan penginderaan jauh, dan untuk membuktikan hasilnya perlu dilakukan observasi, serta dokumentasi untuk mencocokkan terhadap keberadaan RTH Publik eksisting serta strategi pengintegrasian antara RTH Privat dan Pertanian Perkotaan untuk mewujudkan amanah UU-Penataan Ruang di Kota Duri Kabupaten Bengkalis.

Metode kuantitatif berikutnya setelah dilakukan pendekatan spasial menggunakan GIS yang akan dipadupadankan menggunakan Metode AHP. Metode ini untuk menganalisis prioritas kebijakan untuk memenuhi syarat RTH 30\% di wilayah Kota Duri Kecamatan Mandau Kabupaten Bengkalis Provinsi Riau untuk kebutuhan pengintegrasian RTH Privat dengan Pertanian Perkotaan di Kota Duri

Penelitian ini dilaksanakan di Kota Duri yang secara adminstratif termasuk bagian dari wilayah 


\section{ZONA}

Kabupaten Bengkalis yang terdiri dari Kecamatan Bathin Solapan, Kecamatan Mandau dan Kecamatan Pinggir dengan luas wilayah kurang lebih seluas $937,47 \mathrm{~km}^{2}$ dengan jumlah penduduk 256407 jiwa pada tahun 2018. Untuk selanjutnya diskripsi peta administrasi Kota Duri Kabupaten Bengkalis yang disajikan seperti pada Gambar 1.

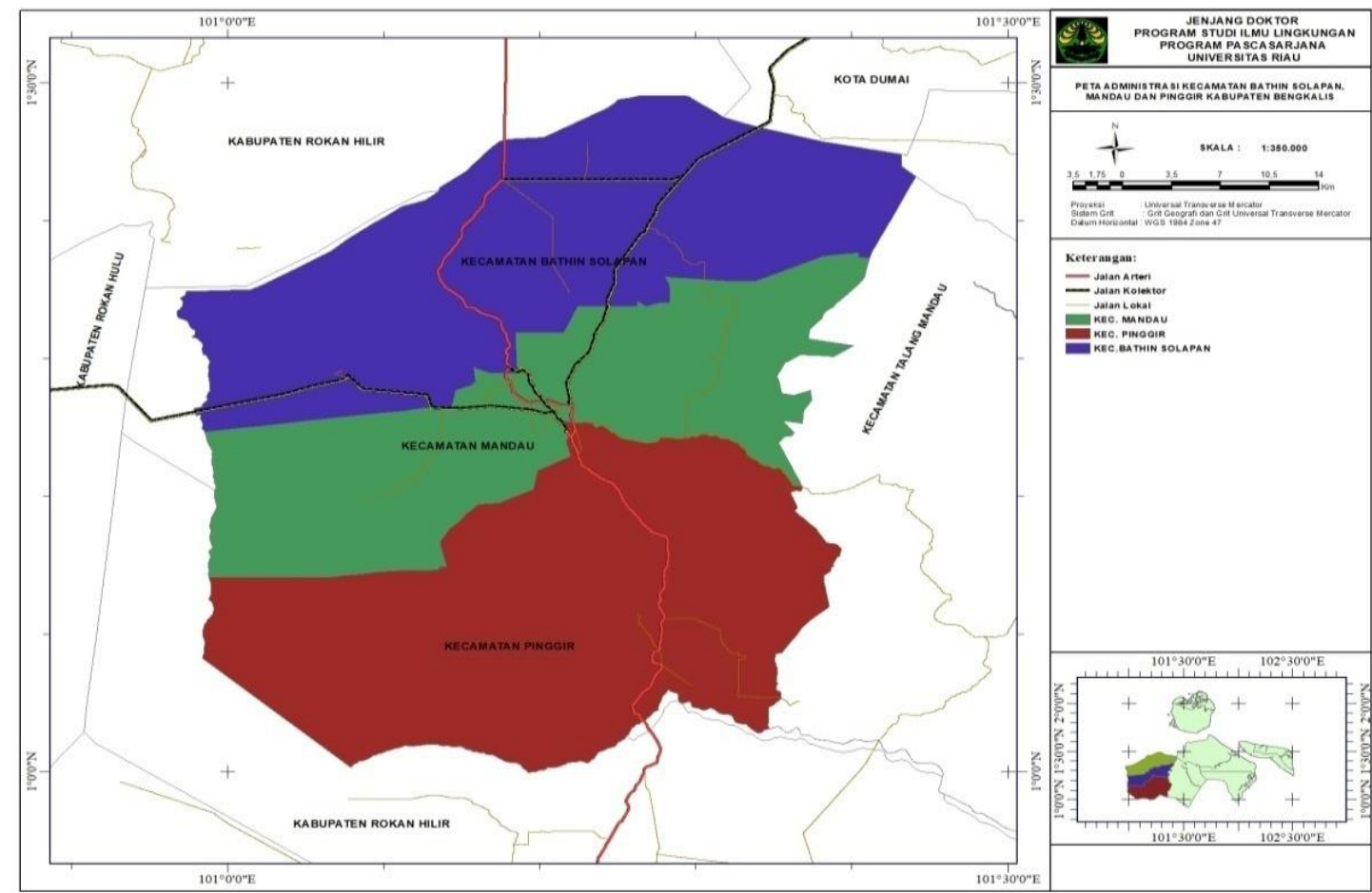

Gambar 1. Peta Administrasi Kota Duri Kabupaten Bengkalis

\section{HASIL DAN PEMBAHASAN}

Strategi ketersediaan RTH 30\% mengamanatkan UU Penataan Ruang Wilayah Republik Indonesia dengan pola integrasi GOS Pribadi 10\% dikombinasikan dengan Pertanian Perkotaan di Kota Duri, Kabupaten Bengkalis Indonesia disajikan seperti Gambar 2.

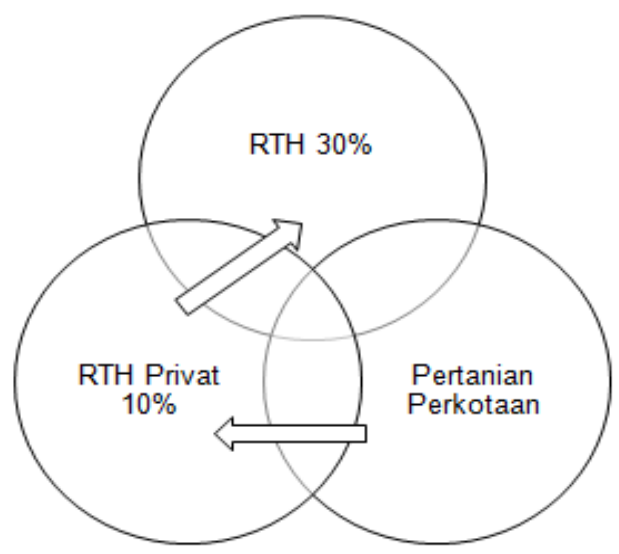

Gambar 2. Hubungan antara RTH 30\%, RTH Privat $10 \%$ dan Pertanian Perkotaan di Kota Duri, Indonesia

Metode pendekatan Analytical Hierarchy Processes (AHP) memiliki keunggulan khusus yang secara sistematis mampu mencocokkan berbagai niat yang saling kompetitif sehingga hierarki pengambilan keputusan untuk mewujudkan RTH 30\% ditetapkan terdiri dari lima tingkatan sebagai berikut level 1 : Tujuan terdiri dari strategi ketersediaan RTH 30\% dengan integrasi antara RTH Swasta dan Praktik 
Pertanian Perkotaan di Duri , Provinsi Riau tingkat 2: Faktor-faktor yang terdiri dari sumber daya manusia, anggaran, infrastruktur dan kebijakan, tingkat 3: Pelaku terdiri dari Pemerintah, Masyarakat, Swasta dan Pendidikan Tinggi (PT), tingkat 4: Sub Purpose terdiri dari Lingkungan, Ekonomi dan Sosial dan tingkat 5 : Aksi terdiri dari komitmen Lingkungan dipertahankan untuk keberlanjutan pembangunan dengan Menerapkan Teknologi Hijau, komitmen Ekonomi dipertahankan untuk keberlanjutan pembangunan dengan Menerapkan Peraturan Ekonomi Hijau dan komitmen Sosial dipertahankan untuk keberlanjutan pembangunan dengan Memperkuat Gerakan Masyarakat.

AHP merupakan salah satu model pengambilan keputusan yang merupakan cabang dari Multi Criteria Decision Making (MCDM) melalui kuesioner dari para ahli yang dinilai kompeten di bidangnya antara lain Kepala Badan Perencanaan Pembangunan Daerah (Bappeda) Kabupaten Bengkalis sebagai pengaturan pengambilan kebijakan pemerintah, Kepala Dinas Perumahan dan Pemukiman Kabupaten Bengkalis dan Kepala Dinas Pekerjaan Umum dan Penataan Ruang adalah Dinas terkait pelaksanaan RTH di Bengkalis , Kepala Dinas Ketahanan Pangan adalah Dinas Ketahanan Pangan Kabupaten Bengkalis dan Dosen Universitas Riau merupakan lembaga yang kompeten berkontribusi pada bidang ilmu pengetahuan untuk mendukung penguatan studi RTH dan Pertanian Perkotaan.

Selanjutnya masih bersumber dari analisis spasial di Kota Duri kondisi yang ada menggunakan GIS, bahwa total pencapaian implementasi RTH Publik di Kota Duri tahun 2018 seperti pada Gambar 3.

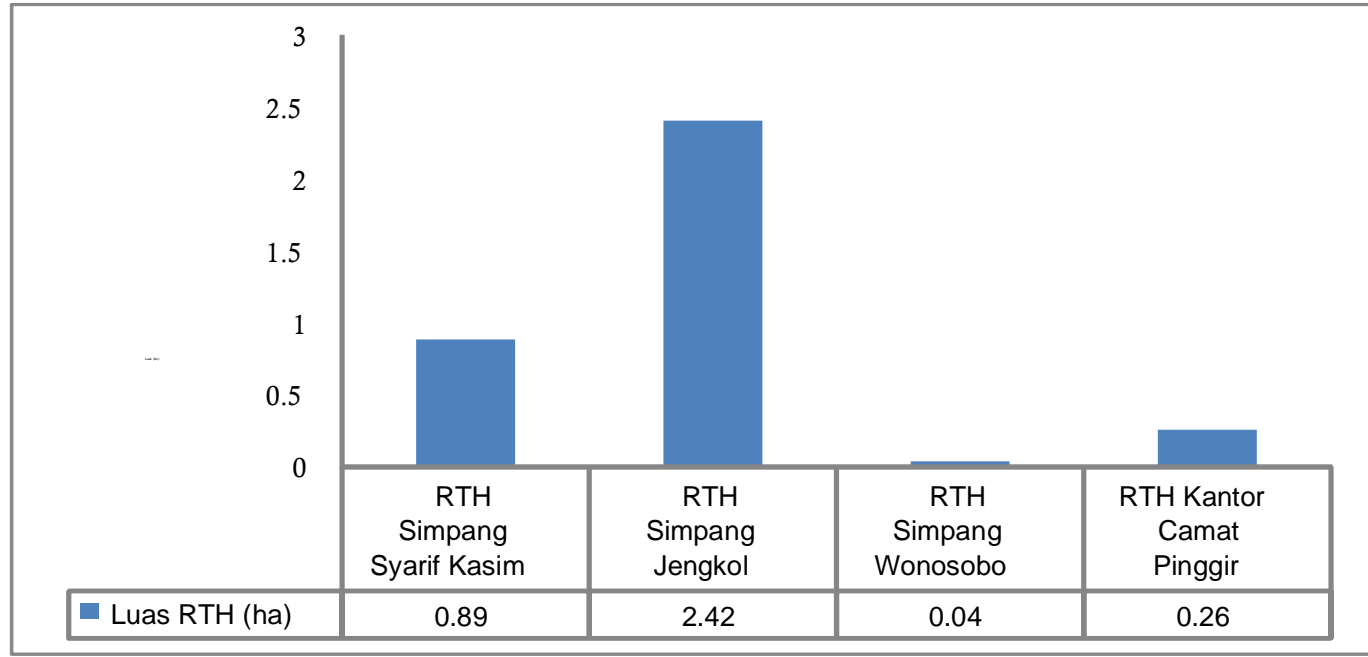

Gambar 3. Diskripsi Eksisting Capaian Ketersedian RTH Publik di Kota Duri Sampai Tahun 2018

Sumber : Analisis Peta Berbasis GIS

Referensi dari Gambar. 3 di atas, perubahan dari jenis tutupan tanah di Kota Duri dari 2014 ke 2018 disajikan seperti dalam Tabel 1 di bawah ini.

Tabel 1. Perubahan Penutupan Lahan di Kota Duri dari Tahun 2014 - 2018

\begin{tabular}{|c|c|c|c|c|c|c|c|c|}
\hline \multirow{3}{*}{ No } & \multirow{3}{*}{\multicolumn{2}{|c|}{ Jenis Penutup Lahan }} & \multicolumn{6}{|c|}{ Kecamatan Dalam Duri Kota } \\
\hline & & & \multicolumn{2}{|c|}{ Tahun 2014} & \multicolumn{2}{|c|}{ Tahun 2018} & \multicolumn{2}{|c|}{ Perubahan Lahan } \\
\hline & & & $\mathrm{Ha}$ & $\%$ & ha & $\%$ & ha & $\%$ \\
\hline 1. & $\begin{array}{l}\text { Hutan } \\
\text { Sekunder }\end{array}$ & Rawa & 471.37 & 0.24 & 391.47 & 0.20 & -79.90 & -0.04 \\
\hline 2. & Hutan Tar & $\operatorname{man}$ & $1,661.21$ & 0.84 & 700.52 & 0.35 & -960.69 & -0.48 \\
\hline 3. & Lahan terk & & $20,027.46$ & 10.10 & 179.47 & 0.09 & $-19,847.99$ & -10.01 \\
\hline 4. & Pemukima & & $3,453.23$ & 1.74 & $3,453.23$ & 1.74 & & \\
\hline 5. & Perkebuna & & $109,695.89$ & 55.31 & $134,533.11$ & 67.84 & $24,837.22$ & 12.52 \\
\hline 6. & Pertambar & & $4,544.76$ & 2.29 & $4,544.76$ & 2.29 & & 0.00 \\
\hline 7. & $\begin{array}{l}\text { Pertanian } \\
\text { Kering }\end{array}$ & Lahan & $9,397.46$ & 4.74 & $9,180.86$ & 4.63 & -216.59 & -0.11 \\
\hline 8. & $\begin{array}{l}\text { Pertanian } \\
\text { Kering } \\
\text { Semak }\end{array}$ & $\begin{array}{r}\text { Lahan } \\
\text { Campur }\end{array}$ & $17,500.27$ & 8.82 & $34,613.73$ & 17.45 & $17,113.45$ & 8.63 \\
\hline 9. & Rawa & & 714.20 & 0.36 & 714.20 & 0.36 & & \\
\hline 10 . & Semak Bel & & & & & & & \\
\hline 11. & $\begin{array}{l}\text { Semak } \\
\text { Rawa }\end{array}$ & Belukar & $30,830.26$ & 15.55 & $9,984.77$ & 5.03 & $-20,845.50$ & -10.51 \\
\hline 12. & Tubuh Air & & 17.63 & 0.01 & 17.63 & 0.01 & & \\
\hline & Luas Penu & p Lahan & $198,313.75$ & 100.00 & $198,313.75$ & 100.00 & 0.00 & 0.00 \\
\hline
\end{tabular}

Sumber: Analisis GIS 
Mengacu pada Tabel. 1 di atas, jenis tutupan lahan untuk luas pemukiman 3.453 ha $(1,74 \%)$ dan Dryland Farm Mixed Bush 34.613,73 ha (17,45\%) dari total luas tutupan lahan di Kota Duri tahun 2018 berjumlah 198.313, 75 ha (100\%). Settlement dan Dryland Farm Mixed Bush merupakan jenis tutupan lahan yang berpotensi untuk dijadikan RTH Swasta yang terintegrasi dengan program pertanian perkotaan, untuk mendukung ketersediaan RTH sesuai dengan amanat UU Penataan Ruang sebesar 30\%.

Selanjutnya, peran dilakukan di setiap tingkat (tujuan, faktor, aktor, sub tujuan dan tindakan) berdasarkan hasil kuesioner penilaian ahli, yang untuk analisis lebih lanjut AHP menggunakan program tambahan yang dikembangkan oleh Simon C Bartrand United Kingdom (SCBUK) Limited.

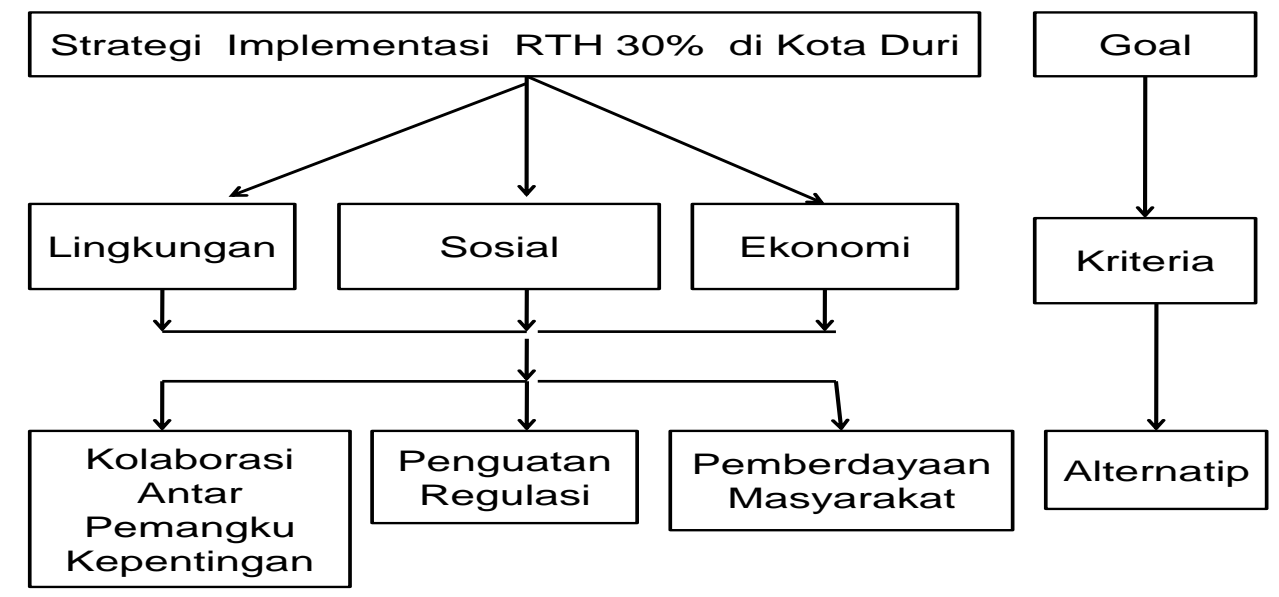

Gambar 4. Hirarki Strategi Implementasi RTH 30\% di Kota Duri

Peran Pemerintah Daerah, Kabupaten Bengkalis sangat dominan dalam upaya inovasi kebijakan melalui Peraturan Bupati, Tentang Program Pertanian Perkotaan dan Penerapan Peraturan Izin Mendirikan Bangunan Plus (IMB Plus) yang membutuhkan 10\% dari total luas bangunan rumah yang akan digunakan sebagai RTH Swasta dengan mengintegrasikan Praktik Pertanian untuk mendukung sektor penguatan lingkungan, ekonomi dan sosial yang berkontribusi pada penambahan kawasan ketersediaan RTH privat sama dengan 345.323 ha atau 0,323 ha atau $0,174 \%$.

Pemerintah daerah, Kabupaten Bengkalis konsisten dan berkomitmen terhadap program implementasi teknologi hijau yang didukung oleh gerakan masyarakat hijaunya diyakini mampu mengembalikan kualitas tutupan lahan pertanian. Penerapan fitoremediasi dan teknologi serta teknologi Eco Drain yang mampu mengendalikan run off serta penambahan proses infiltrasi akan mampu mengembalikan kesuburan tanah sehingga dapat difungsikan menjadi pertanian perkotaan non pangan, restorasi kualitas lahan pertanian seluas $80 \%$ dari total luas tutupan lahan pertanian kering bercampur semak belukar, dengan menerapkan teknologi hijau, akan berkontribusi pada penambahan availability area RTH di Kota Duri sebesar 27,690.984 ha atau setara 13,96\%. Penambahan ketersediaan RTH akan berdampak signifikan pada peningkatan lingkungan, perekonomian dan sosial masyarakat di Kota Duri. Jumlah total antara kawasan pemukiman dan pertanian lahan kering sebesar $0,174 \%$ ditambah $13,96 \%$ sebesar $14,134 \%$.

\section{KESIMPULAN}

Integrasi strategis RTH Privat dengan Program Pertanian Perkotaan menggunakan pendekatan GIS-AHP di Kota Duri menyumbang ketersediaan RTH Private sebesar 14,134\%, sehingga RTH privat telah melampaui batas persyaratan minimal 10\% berdasarkan amanat UU Penataan Ruang, Republik Indonesia.

\section{DAFTAR PUSTAKA}

Asiani, Y. (2007). The Effect of Green Open Space Conditions on Micro Climate in Bogor City . Depok. Indonesia of University.

Blyth, A and L. Menagh. (2006). From Rooftop to Restaurant : A University Café Fed by A Rooftop Garden.The Canadian Organic Grower: 55.

Chandran, R. (2020). Grow your own: Urban farming flourishes in coronavirus lockdowns. Thomson Reuters Foundation News. April 23 https://news.trust.org/item/20200407082542-5652d/ 
Cofie, O., A. Bradford, and P. Drechsel. (2006). Recycling of urban organic waste for urban agriculture. Cities Farming for the Future; Urban Agriculture for Green and Productive Cities" by René van Veenhuizen (ed.), RUAF Foundation, the Netherlands, IDRC, Canada and IIRR publishers, the Philippines, 2006.

Dongyu, Q., Adhanom Ghebreyesus, T. and Azevedo, R. (2020). Mitigating impacts of COVID-19 on food trade and markets.http://www.fao.org/news/story/en/item/1268719/icode/. 19.4.20.

Dzulfaroh, A. N. (2019). Global Hunger Index Research: Indonesia in serious category. https://www.kompas.com/tren/read/2019/12/03/163603665/riset-indeks-kelaparan-globalindonesia-dalam-kategori-serius?page=all.

Loker., A, and Francis, C. (2020). Urban food sovereignty: urgent need for agroecology and systems thinking in a post- COVID-19 future. Agroecology and Sustainable Food Systems.

Estoque, R. C., Murayama, Y. and Myint, S. W. (2017). Effects of Landscape Composition and Pattern on Land Surface Temperature: An Urban Heat Island Study in The Megacities of Southeast Asia. Science of the Total Environment, 577 : 349-359.

Koscica, M. (2014). The Role of Urban Agriculture in Addressing Food Insecurity in Developing Cities. Journal of International Affairs. 67 (2) : 177-186.

Lal, R. (2020). Home gardening and urban agriculture for advancing food and nutritional security in the respone to the Covid-19 pandemic, Food Security. : 872-876.

Pinderhughes, R. (2004). Alternative urban futures: Planning for sustainable development in cities throughout the world. Lanham, Boulder, New York, Toronto. New York (NY) : Oxford, Rowman \& Littleield Publishers.

Rawung, F. C. (2015). Effectiveness of Green Open Space in Reducing Greenhouse Gas Emissions in Boroko Urban Areas. Media Matrasains, 12(2) : 17-32.

Setiawan, B. and Rahmi, D, H. (2004). Food Security, Employment, and Urban Sustainability : Study of Urban Agriculture in Six Cities in Indonesia. 2004. Research News Gadjah Mada of University (special edition) : $34-42$.

Smith, J., J. Nasr., Ratta, A., (2001). Urban Agriculture, Food, Jobs, and Sustainable Cities. United Nations Development Programme.

Specht, K., Siebert, R., Hartmann, I., Freisinnger, U, B., Sawicka, M., Werner, A., Thomaier, S., Henckel, D., Walk, H. and Dierich, A. (2014). Urban agriculture of the future: an overview of sustainability aspects of food production in and on buildings. Agriculture Human Values. 31: 33-51.

Undang-Undang Nomor: 26 Tahun 2007 Tentang Penataan Ruang.

Wolfe, J, M. and Mc Cans, S. (2009). Designing For Urban Agriculture in An African City: Kampala, Uganda. Open House International. 34(2): 25-35.

Zezza, A. and Tassciotti, L. (2010). Urban agriculture, poverty, and food security : empirical evidence from a sample of developing countries. Food Policy 35: 265-273.

Yu, W., Zang, S., Wu, C., Liu, W. and Na, X. 2011. Analyzing and Modeling Land Use Land Cover (LULC) in the Daqing City, China, Applied Geography, 31: 600-608. 